\title{
Josefina Molina y Función de noche (1981): la deconstrucción de la socialización femenina durante el Franquismo a través del cine $^{1}$
}

\section{Resumen}

La Transición española hacia la democracia (1975-1982), tras cuarenta años de dictadura bajo el mando del General Franco, fue un periodo muy complejo en el que la población española tuvo que aprender a vivir bajo nuevos parámetros y a dejar atrás hábitos y formas de relacionarse adquiridos bajo el régimen anterior nacional catolicista, fuertemente conservador. Junto al apoyo legislativo, fue necesario un compromiso de todos los agentes socializadores para construir una nueva España más libre y humana. Uno de ellos es el cine. Numerosos cineastas se adhirieron a este objetivo, y entre ellos destaca la figura de Josefina Molina, una de las pocas mujeres directoras, que anima a una reflexión sobre la perversa educación recibida por las mujeres bajo la etapa franquista a través de su filme Función de noche (1981). El objetivo de este trabajo es realizar un análisis del modelo de mujer característico del Franquismo que nos presenta esta película. Un modelo que posiblemente sea identificable en otras regiones del planeta puesto que es característico de las sociedades patriarcales. El núcleo central del artículo es el análisis de la estructura organizativa y del contenido del filme pero antes lo contextualizamos mediante un acercamiento a los roles clásicos adjudicados a hombres y mujeres a través de la socialización diferencial. Terminamos con unas reflexiones sobre las principales conclusiones de nuestro trabajo que buscan suscitar en el público lector una actitud crítica y de compromiso con la construcción de un mundo más equitativo y justo.

Palabras clave: Estudios de género. Historia de la educación. Mujer y Cine. Josefina Molina. Función de Noche.

\section{Para citar este artigo:}

GUICHOT-REINA, Virginia. Josefina Molina y Función de noche (1981): la deconstrucción de la socialización femenina durante el Franquismo a través del cine. Revista Linhas. Florianópolis, v. 21, n. 47, p. 133-164, set./dez. 2020.

\section{DOI: $10.5965 / 1984723821472020133$}

http://dx.doi.org/10.5965/1984723821472020133

\footnotetext{
${ }^{1}$ Este trabajo se ha desarrollado bajo el marco del proyecto Economía, patriotismo y ciudadanía: La dimensión económica de la socialización política en los manuales escolares españoles desde el Tardofranquismo hasta la Transición (Ministerio de Economía y Competitividad, EDU2016-78143-R).
} 


\section{Josefina Molina and Función de noche (1981): the deconstruction of female socialization during the Francoist regime from the cinema}

\section{Josefina Molina e Función de noche [Sessão nocturna] (1981): a desconstrução da socialização feminina durante o regime de Franco através do cinema}

\begin{abstract}
Spanish Transition to democracy (1975-1982), after forty years in dictatorship with General Francisco Franco, was a very complex period where Spanish people had to learn to live with new criteria and to leave many habits and ways of being in contact with other people acquired during the strongly conservative Francoist Regime. In addition to the legislative support, it was necessary a commitment by all the agencies of socialization in order to build a freer and more human Spain. One of them is the cinema. Numerous filmmakers looked for this aim and the person of Josefina Molina stood out between them. She was one of the few women directors who wanted to encourage a reflection on the perverse education received by women during the Francoist regime through her film Función de noche (1981). This paper aims to analyse the model of woman of the Francoist Regime that the film shows; a model that could also be identified in other areas of Earth because it is typical in patriarchal societies. The core of this paper is the analysis of the organizational structure and the content of the film but, first, we contextualize the film using an approach to the classic roles assigned to women and men though differentiating socialization. We finish with some reflections on the main conclusions of our paper, trying to encourage a critical and committed attitude in our readers for the construction of a fairer and more equitable World.
\end{abstract}

Keywords: Gender Studies. History of Education. Woman and Cinema. Josefina Molina. Función de noche.

\section{Resumo}

A transição espanhola para a democracia (19751982), após quarenta anos de ditadura sob o comando do General Franco, foi um período muito complexo em que a população espanhola teve de aprender a viver sob novos parâmetros e a deixar para trás hábitos e formas de relacionamento adquiridos sob $\mathrm{o}$ anterior regime fortemente conservador e nacionalcatólico. Juntamente com o apoio legislativo, foi necessário um compromisso de todos os agentes socializadores para construir uma Espanha nova, mais livre e mais humana. Uma delas é o cinema. Muitos cineastas aderiram a este objectivo, e entre eles destaca-se Josefina Molina, uma das poucas realizadoras, que encoraja a reflexão sobre a educação perversa recebida pelas mulheres sob o regime franquista através do seu filme Función de noche (1981). O objectivo deste trabalho é fazer uma análise do modelo de mulher característico do franquismo apresentado neste filme. Um modelo que é possivelmente identificável noutras regiões do planeta uma vez que é característico das sociedades patriarcais. O núcleo do artigo é a análise da estrutura organizacional e do conteúdo do filme, mas primeiro contextualizamo-lo abordando os papéis clássicos atribuídos a homens e mulheres através da socialização diferencial. Terminamos com algumas reflexões sobre as principais conclusões do nosso trabalho que procuram provocar no público leitor uma atitude crítica e empenho na construção de um mundo mais equitativo e justo.

Palavras-chave: Estudos de gênero. História da Educação. Mulheres e Cinema. Josefina Molina. Función de Noche. 


\section{Introducción}

Una de las etapas más relevantes en la historia reciente española es la conocida con el nombre de "la Transición", que comenzó en noviembre de 1975, con la muerte del general Francisco Franco, y terminó en octubre de 1982, con la victoria en las elecciones generales por mayoría absoluta del Partido Socialista Obrero Español (PSOE). Tras cuarenta años de dictadura, España inició su andadura hacia la democracia, poniéndose en marcha progresos decisivos en todos los ámbitos para la población y, en particular, para las mujeres. Sin duda, el principal logro legislativo en la consecución de la igualdad de derechos y libertades para las féminas españolas respecto de los hombres fue la aprobación de la Constitución de 1978 que declara, en su artículo 14, que "los españoles son iguales ante la ley, sin que pueda prevalecer discriminación alguna por razón de nacimiento, raza, sexo, religión, opinión o cualquier otra condición o circunstancia personal o social” (BOE, 29 de diciembre de 1978). Diversas leyes y disposiciones se promulgaron para apuntalar esta importante victoria jurídica, como la Ley 11/1981 de modificación del Código Civil en materia de filiación, patria potestad y régimen económico del matrimonio o la Ley 30/1981 de derecho al divorcio.

Durante el recién terminado régimen franquista, se había puesto claramente de manifiesto el destino marcado para las mujeres que no era sino el de "madreesposa”, pero a medida que el Franquismo fue avanzando en el tiempo, en lo que se conoce como Tardofranquismo -fundamentalmente década de los sesenta hasta 1975- se percibieron ciertas rupturas con el modelo tradicional. Por ejemplo, la especialización de la economía española en el sector servicios a partir de la década de los sesenta del siglo pasado incrementó la demanda de empleo femenino, favoreciendo la progresiva incorporación de las mujeres al mercado laboral (CAPEL, 2002; FLECHA, 1989). De este modo, se inició una revalorización del rol femenino que supuso concebir a la mujer española más allá de su exclusiva función doméstica (MORENO-SECO, 2008; PÉREZ MORENO y GONZÁLEZFARACO, 2014). En el terreno educativo, con el fin de unificar y democratizar la enseñanza y promover el fomento de la igualdad de oportunidades entre mujeres y hombres, se promulgó la Ley 14/1970, de 4 de agosto, General de Educación y Financiamiento de la 
Reforma Educativa (LGE). Dicha ley quería eliminar cualquier tipo de discriminación laboral y educativa, garantizando una educación gratuita y de calidad a toda la población.

Durante la Transición, Mora (2012) destaca diversas organizaciones que reivindicaron los derechos de la mujer y denunciaron la situación de crisis económica que se estaba viviendo en los hogares españoles a raíz de la crisis del petróleo (1973), como la Asociación de Amas de Casa o el Movimiento Democrático de Mujeres (MDM). En concreto, el MDM, vinculado al Partido Comunista (PCE), animó a las españolas a interesarse no solo por los asuntos públicos y políticos del país en general, sino especialmente por los vinculados con la discriminación de las mujeres en particular (ALONSO y FURIO, 2007). Este asociacionismo y unión de mujeres expresaba el fuerte deseo de la población femenina en la creación de una identidad colectiva de mujeres renovada, inconformista, que se atrevía a entrar en ese espacio público hasta entonces considerado "masculino" y a defender los valores igualitarios en cuestiones de género (MORENO, 2017; MORENO 2013). Esta etapa histórica supuso un marco ideal para el desarrollo de la mujer y auge del movimiento feminista y sus reivindicaciones (BAUTISTA, 1996; GALVÁN, 2013; VILCHES, 2014). El feminismo consiguió que temáticas como la igualdad, el divorcio, los anticonceptivos, la conciliación laboral, etc., se convirtieran en propias del quehacer político, laboral, educativo, etc., durante el traspaso a la democracia española (MORA, 2012).

Ahora bien, un fuerte sistema patriarcal de la sociedad, fruto de siglos, acentuado por un régimen autoritario y conservador como el franquista, no pudo ser desmontado únicamente a base de leyes, decretos y declaraciones institucionales y buenas intenciones. Exige de un compromiso por parte de los principales agentes educativos/socializadores y uno de ellos, sin dudas, es el cine que, si en nuestros días tiene aún una fuerte presencia, mucho más en la época de la Transición (1975-1982), en la que aún no competía con el todopoderoso Internet ni con las numerosas alternativas que oferta hoy en día la televisión privada.

Una etapa de profundos cambios como la de la Transición afectó sobremanera a la filmografía realizada en España. Tal como indica Ramírez Gómez (2011, p. 125), "Con la llegada de la Transición surgió una corriente de cineastas que querían romper con todo lo 
anterior y que pedían una renovación formal y temática. Poco a poco nos hicimos europeos y nos empapamos del cine de nuestros países colindantes". Junto a filmes con un objetivo de mero entretenimiento, aparece un nuevo cine crítico, comprometido con la libertad y, progresivamente, con unos niveles de calidad comparables al que se hacía en otros países occidentales. Un cine que intentaba juzgar el pasado más próximo para construir un presente libre de tabúes y represiones y encaminado a asegurar la libertad de la ciudadanía (LOMA, 2013, p. 43). Los cineastas presentan temas hasta entonces prohibidos y van aproximándose a las pautas creativas del resto del mundo, lo que da lugar a avances muy profundos en el plano formal y material. Ello lleva a que expertas como Loma (2013) afirmen que la Transición inicia de manera imparable la construcción de un cine políticamente más libre, culturalmente más rico y técnicamente más desarrollado en España. Al respecto, indica Ruzafa (2004, pp. 11-12):

Lo hizo en cuanto a lenguajes, valores, dimensiones y temas. Fenómenos como la emancipación de la mujer, la revisión de la guerra civil 1936-1939 y el franquismo, el regreso de los exiliados, el acceso a las libertades fundamentales, el terrorismo, el temor a la involución política y la crisis económica se asomaron lo mismo a las tribunas que a las pantallas.

Las pocas mujeres directoras asumen fuertemente el compromiso de construir una nueva España más libre y humana y, especialmente, advierten la necesidad, bajo la bandera de feminismo, de lograr sacar a las mujeres de la situación de represión que sufrían debido a la socialización recibida durante la etapa franquista. Tres mujeres son clave en esta misión: Cecilia Bartolomé, Pilar Miró y Josefina Molina, a las que podemos unir con tres filmes auténticamente revolucionarios: ¡Vámonos, Bárbara! (1977), Gary Cooper que estás en los cielos (1980) y Función de noche (1981). Nosotras nos ocuparemos de este último que ha sido calificado como

el primero en dar voz a la mujer de esa época en su reivindicación de su subjetividad y de su lugar en la sociedad, en pie de igualdad con el hombre, igualdad de la que ha carecido hasta entonces. En este sentido el filme de Josefina Molina se convierte en una obra pionera y en pieza clave de la cinematografía de la Transición. (LOMA, 2013, p. 310) 
El objetivo de este trabajo es realizar un análisis del modelo de mujer característico del Franquismo que nos presenta la película Función de noche (1981) y que nos revela la socialización recibida por las féminas en ese oscuro periodo de la historia de España. Un modelo que posiblemente sea identificable en otras regiones del planeta puesto que es característico de las sociedades patriarcales. En primer lugar, creemos necesario establecer algunas reflexiones sobre la construcción de la identidad personal y revelaremos el tipo de socialización diferencial que reciben hombres y mujeres desde el nacimiento centrándonos en los roles tradicionales que se les han asignado. Haremos hincapié en el papel del cine como agente educativo y el fuerte potencial que posee en la configuración de conductas gracias a su capacidad de mover emociones y sentimientos.

Seguidamente, nos centraremos en el filme Función de noche (1981), a través de un acercamiento a su directora, a su vida y objetivos vitales mediante su producción artística; una parada necesaria en la obra de teatro Cinco horas con Mario que impulsó la realización de la película; y un análisis de la estructura organizativa y de contenido del filme, núcleo central de este artículo. Terminamos con unas reflexiones que intentan sintetizar las principales conclusiones de nuestro trabajo y suscitar en el público lector una actitud crítica y de compromiso en la construcción de un mundo más equitativo y justo.

\section{Socialización y construcción de la identidad masculina y femenina. El cine como agente socializador}

Desde el momento de su nacimiento, el ser humano está sometido a un proceso de socialización por parte del medio cultural que le rodea. Va interiorizando los valores, las normas y las costumbres de la sociedad en la que le ha tocado vivir; aprendiendo las conductas que se consideran positivas y negativas y las competencias con las que podrá adaptarse exitosamente en la interacción con los demás. Tal como señalara Burr (1995), el individuo toma contacto con los discursos disponibles social y culturalmente que le remitirán a elementos esenciales de su existencia, como, por ejemplo, qué se considera propio de cada género, cuál es la "buena educación”, con qué profesiones se obtiene 
mayor reconocimiento y/o remuneración, etc. Estos discursos van a proporcionar al sujeto una forma de interpretar y de dotar de significado al mundo y a las personas que lo habitan.

Si bien todos los seres humanos pasamos por el proceso de socialización, ésta difiere notablemente según variables como el lugar en el que vivimos o la clase social. Nosotros, dado el propósito de este artículo, vamos a detenernos en la variable género, que influye de forma manifiesta en los roles que se nos asignan dentro de la comunidad. El género no debe ser visto como una propiedad inmutable de los individuos, sino como un hacer, es decir, un proceso en continuo cambio y construcción de cada persona vinculado a su papel e interacción social, política, cultural y económica con los demás miembros de la sociedad (WEST y ZIMMERMAN, 1987). La Organización de Naciones Unidas lo define como el conjunto de características sociales, culturales, políticas, psicológicas, jurídicas y económicas que la sociedad asigna a las personas de forma diferenciada como propias de hombres y mujeres; y recalca que los géneros son construcciones socioculturales que varían a través de la historia y se refieren a los rasgos psicológicos y culturales que la sociedad atribuye a lo que considera "masculino" o "femenino" mediante la educación, el uso del lenguaje, la familia, las instituciones o la religión (ONU, 2006). En definitiva, los roles que tradicionalmente se atribuyen a mujeres y hombres no sin innatos ni naturales sino aprendidos -y por tanto, cuestionables y modificables-.

Elena Simón (2011), en su obra La igualdad también se aprende. Cuestión de coeducación, nos detalla cómo desde la más tierna infancia, niñas y niños se proyectan e intentan ajustarse a los patrones establecidos socialmente y transmitidos por su entorno más próximo como la familia, los iguales con los que se relacionan o los medios de comunicación a los que acceden. A menudo, los niños varones aprenden a divertirse con la acción, el control de máquinas, el manejo de herramientas, el dominio del espacio, e interiorizan valores como la competitividad o la capacidad de iniciativa. Paralelamente, un porcentaje elevado de niñas son animadas hacia juegos en los que la estética corporal, el cuidado o la atención personal cobran gran importancia y van asumiendo valores como la empatía, la solidaridad o la capacidad de diálogo. Las consecuencias son previsibles: 
Estas serán las orientaciones de sus proyectos biográficos en la juventud y las bases fundamentales de sus existencias en la edad adulta, que conllevan usos del tiempo desigualmente remunerados, ocupación de espacios desigualmente remunerados, o prioridades desigualmente beneficiosas para ellas o para ellos. (SIMÓN, 2011, p. 64)

Sobre hombres y mujeres recaen distintas expectativas sociales que se traducen en diferentes roles, diferencias muchas más acusadas en aquellas sociedades que podemos calificar como "conservadoras”, como era la franquista, donde había recibido su educación los protagonistas del filme que vamos a examinar, Lola Herrera y Daniel Dicenta. Un somero repaso a estos imperativos tanto masculinos como femeninos proporcionará un marco teórico al análisis de contenido que vamos a realizar de Función de noche (1981).

Moore y Gillette, en su libro La nueva masculinidad (1993), describen cuatro roles ligados a la masculinidad clásica, roles que, ejercidos en su parte más negativa -y tradicionalmente, la más habitual- conllevan graves perjuicios no sólo para las mujeres sino también para los propios hombres. Son los roles de guerrero, mago, amante y rey. El primero, el de guerrero, se vincula con conductas de riesgo y trasgresión, con luchas, enfrentamientos y uso frecuente de la violencia como fuente para solucionar los conflictos. El rol de mago se asocia a la prepotencia en el conocimiento -a veces, incluso sin fundamento real-, a la arrogancia en el saber unida a una tendencia a querer imponer la opinión propia.

En cuanto al amante, en su vertiente negativa, se relaciona con el deseo sexual exigente, exhibicionista; muchas veces buscando el control corporal, sexual y reproductivo de las mujeres. Por último, el rol de rey supone un papel de mando, de poder y de riqueza, en busca de la sumisión y admiración de todos quienes le rodean. Hemos mostrado la cara negativa de estos cuatro roles pero Moore y Gillette animan a desempeñarlos a través de nuevas fórmulas que derivarían en una eficaz competencia instrumental y de control psicológico o físico para soportar condiciones extremas (guerrero); la búsqueda de nuevos descubrimientos e inventos que posibiliten avances científicos y tecnológicos para la Humanidad (mago); el amor y la empatía hacia sus parejas (amante); y la capacidad de liderazgo no autoritario (rey). 
La efectividad de estos roles clásicos, esto es, la posibilidad de que se puedan ejercer con éxito, necesita dos condiciones: a) las mujeres y los hombres no dominantes deben satisfacer de manera complementaria las exigencias que emanan de estos roles hegemónicos y b) la existencia de sistemas de socialización/educación encargados de transmitirlos (familia, escuela, grupo de iguales, medios de comunicación de masas como el cine, etc.).

Frente a estos roles masculinos, existen los complementarios adjudicados a la feminidad clásica. Amelia Valcárcel realiza un análisis espléndido en su libro Feminismo para un mundo global (2008). Ella utiliza el término "leyes" para referirse a mandatos explícitos y/o implícitos, enseñados y aprendidos por imitación y repetición, que reciben las mujeres en su conjunto, existiendo cinco leyes básicas dirigidas a las féminas: agrado, cuidado, laboriosidad, entrega y detalle. Todas conducen a la sumisión y subordinación afectiva de las mujeres. Esas leyes las veremos luego ejemplificadas en la deconstrucción de su identidad como mujer que hace Lola Herrera en Función de noche.

La ley del agrado lleva a las mujeres a que interioricen la idea de que lo importante es "gustar" y que "te quieran", de forma que el logro de dicho objetivo se revela como indicativo de éxito vital. Nótese que lo realmente valioso es la mirada ajena, el aprecio del otro. Para conseguir dicho propósito, muchas féminas esconden sus pensamientos y deseos, se callan su opinión, ocultan su desagrado o enfado... si creen que, en caso contrario, pueden perder el aprecio y el amor de los hombres. La ley de cuidado se manifiesta en una atención constante a la pareja y a los hijos e hijas por parte de las mujeres -sin que los varones hagan algo similar-, relegando a un segundo plano sus aficiones, renunciando a un tiempo de ocio o incluso a su promoción profesional cuando piensan que les puede dificultar desarrollar esa labor de cuidado a la perfección.

La ley de la laboriosidad se materializa en la actualidad de dos formas: el buen rendimiento educativo y la formación continuada; y la doble jornada, laboral y doméstica. Estos rasgos impulsan a que las féminas estén siempre ocupadas, sin tiempo libre para el disfrute personal. Décadas atrás, esta ley empujaba a las mujeres a pasar el día entero volcadas en trabajos domésticos, desde la limpieza del hogar a preparar todo tipo de comidas de exigente elaboración. Este es el desglose de los roles y leyes "clásicos", los 
correspondientes a las sociedades patriarcales hegemónicas y, por consiguiente, aquellos con los que habría que romper si nuestra aspiración es conseguir un mundo más justo donde las mujeres no tengan un papel secundario, de subordinación a una hegemonía masculina.

El cine es un agente de socialización. Señala Reía-Baptista (2012, p. 86) que es el más ecléctico y sincrético de todos los medios de comunicación de masas, y posee un enorme poder de atracción que se replica en otros mass media mediante la utilización de lenguaje cinematográfico en todo tipo de contextos: imágenes reales para optimizar los videojuegos, vídeos musicales para promocionar música, actores y actrices de renombre para cubrir objetivos publicitarios, extractos de filmes de "YouTube"o "Facebook", etc. Esta capacidad seductora está muy relacionada con su potencial para mover el mundo de los sentimientos y los afectos a través de la comunicación verbal y no verbal que realizan los diferentes elementos que componen una película: gestos, actitudes y posturas de los personajes, la música, el montaje de las escenas, la fotografía, los efectos especiales, entre otros (GUICHOT-REINA, 2017).

Este fuerte poder de repercutir en el mundo afectivo, dirigidos a que las ideas y pensamientos ligados a las emociones se afiancen con mayor fuerza en nuestras estructuras cognitivas, es esencial en el campo de la socialización. Las películas cuentan historias, esto es, son narraciones y éstas interaccionan con las que conforman nuestra identidad personal y pueden contribuir a reafirmarla o transformarla añadiendo nuevos significados, novedosas formas de enfrentarse a la realidad. Este parece que fue precisamente uno de los principales objetivos de las pocas mujeres directoras que encontramos en el período de la Transición española, entre ellas Josefina Molina, quienes pretendieron proporcionar nuevos referentes emancipadores a las féminas que superasen los obsoletos y perjudiciales modelos femeninos proporcionados por el Franquismo -que respetaban las leyes femeninas recién descritas-:

el cine de las mujeres directoras en la Transición, en líneas generales es un cine que prefiere el drama, con ideas originales, no basadas en obras literarias, protagonizadas por mujeres en la época actual a la producción y bajo el tema de la transformación personal como camino hacia la libertad. 
Se trata, por tanto, de un tipo de relatos comprometidos con su tiempo y con su género, como mujeres en una España también en transición hacia la libertad democrática, asumiéndola y enraizándola. (GUARINOS, 2016, p. 93)

Directoras comprometidas, rompedoras y feministas, que pusieron su granito de arena para conformar un mundo más justo y más libre, tarea que deberíamos asumir todos los seres humanos. A Josefina Molina y a su magistral obra Función de noche (1981) dedicamos el siguiente apartado.

\section{Función de noche (1981): directora, contexto de producción y análisis de contenido}

\section{a) Josefina Molina Reig, una directora comprometida con el feminismo}

Sería inconcebible pensar en la creación de una película como Función de noche sin la apuesta comprometida y valiente de su directora, Josefina Molina. Una cordobesa, nacida el mismo año del comienzo de la guerra civil española, 1936, quien, tras superar primero unas duras pruebas de acceso ${ }^{2}$, fue la primera mujer en titularse en Dirección en la Escuela Oficial de Cinematografía, en 1969. Una mujer que, en un momento donde muy pocas féminas estudiaban, menos aún en niveles superiores a la primaria, había adquirido una sólida formación primero en el colegio de los Hermanos de la Salle y luego en las Escolapias de Santa Victoria, gracias al apoyo de su madre, sabedora de que instrucción y libertad van de la mano, y al nivel económico de su familia burguesa, (LOMA, 2013, p. 37).

Aunque inicia sus pasos profesionales dentro de la dictadura franquista, en la etapa que se ha denominado "Tardofranquismo", sus obras más personales, originales y de mayor éxito de taquilla se van a producir ya en la Transición española (1975-1982). Hija de

\footnotetext{
2 En 1963, Josefina Molina, tras abandonar los estudios que había iniciado de Ciencias Políticas, decide ingresar en la Escuela Oficial de Cinematografía. Se presentaron ciento tres aspirantes (seis de ellos mujeres) a las pruebas de acceso en la especialidad de Dirección. Sólo las superaron ocho personas y ella fue la única mujer: Álvaro del Amo, Miguel Bilbatúa , José María Casaux, Rafael Henríquez, José Luis García Sánchez, Antonio Lara, Josefina Molina y Juan Tébar. El tribunal estaba compuesto por cuatro eminentes figuras de la cinematografía española: Luis García Berlanga, José Luis Sáenz de Heredia, Carlos Serrano de Osma y Florentino Soria. En 1969 se tituló con su práctica Melodrama infernal (LOMA, 2013, p. 39).
} 
su tiempo, integrante de ese grupo de representantes de la cultura comprometidos con la idea de que había que cambiar las formas de pensar, y por tanto de ser, que habían sido hegemónicas durante el recién terminado régimen autoritario (FORNIELES, 2007, p. 421), Molina quiere recoger en sus obras, mucho más en Función de noche (1981), la mirada femenina a los problemas de la mujer de su época. Declarada feminista, apuesta por la idea de una "identidad femenina", animando a las mujeres a que repiensen los imperativos patriarcales que han ido interiorizando mediante la socialización recibida desde su infancia. Y a ello se dedica en Función de noche, a través de la soberbia interpretación de una actriz, Lola Herrera, de su misma generación y por tanto con la interiorización de los mismos "mandatos" destinados a la mujer que había recibido ella por parte de una sociedad altamente machista.

Aprovecha además la absoluta necesidad que la propia actriz le revela de sacar toda la angustia y desazón que llevaba dentro, todo aquello que quería haberle dicho a su expareja y padre de sus dos hijos, del que se había separado hacía quince años, y que nunca se atrevió a comunicarle. Josefina y Lola, directora y actriz, ambas unidas y convencidas de que, exteriorizando todas las lecciones y actitudes que el franquismo había impuesto a la condición femenina, degradándola, podían ayudar a muchas mujeres a que, reconociéndose en la protagonista del filme, fueran capaces de efectuar una labor de deconstrucción de su identidad con vistas a desechar todo lo indeseable y creador de insatisfacción y a apuntar hacia nuevos rumbos, hacia un nuevo modelo de mujer más autónoma, más independiente, más libre que, sin embargo, no adopta tampoco los tradicionales roles masculinos. Al respecto, comenta la propia Molina:

En mis películas, series y teatro siempre hay un personaje femenino que lucha contra la opresión. Yo he hecho mi lucha y he puesto mi acento en personajes que defienden su libertad [...]. Soy feminista porque soy mujer y entiendo que el feminismo no es lo contrario del machismo. Critico el feminismo y el machismo cuando son excluyentes. Creo en el feminismo porque nos ha ayudado a conseguir logros como el voto, pero no deseo hacer lo mismo que los hombres han hecho con nosotras. Hay una identidad femenina y no podemos perderla. (CASTAÑEDA, 1998, p. 45) 
Queremos hacer hincapié en la importancia que tiene, a nuestro entender, esa mirada femenina sobre la mujer. Sin duda, las féminas habían estado presentes en el cine desde sus comienzos pero se las representaba a través de la imagen que de ellas poseía los varones, que eran en la inmensa mayoría de los casos los directores y guionistas. En el cine franquista, tal como recuerda Castejón (2004, p. 314), la mujer solía ser mostrada como la depositaria de virtudes conservadoras como la obediencia o sumisión a la autoridad masculina y divina, la fidelidad, el sacrificio... promulgadas por el Régimen y acordes con el papel que se esperaba de ella de "madreesposa" o bien, ya en los últimos años del Tardofranquismo (años sesenta y principios de los setenta) y en la Transición, como objeto del deseo masculino en las comedias del destape o del conocido como "landismo" -nombre dado por el actor protagonista de gran parte de esas películas que quería ser el estereotipo del español medio, Alfredo Landa-3. Incluso en directores de la llamada "tercera vía" como José Luis Garci, se encuentran clichés hacia el mundo femenino en películas de tremendo éxito en la Transición como Asignatura pendiente (1977) y Solos en la madrugada (1978) y se hallan muy lejos de plantear nuevos referentes femeninos positivos (GUICHOT-REINA, 2019).

Frente a esta visión masculina del mundo femenino, se alzan en la Transición tres mujeres directoras ligadas a tres obras que sirvieron de referentes fundamentales para las féminas de ese momento histórico: Cecilia Bartolomé con su filme ¡Vámonos, Bárbara! (1977), Pilar Miró, con Gary Cooper que estás en los cielos (1980) y, por supuesto, Josefina Molina con Función de noche (1981). Las tres presentan mujeres que rompen con los estereotipos femeninos que solían ser extendidos a través de las películas, personas reflexivas, que se cuestionan las normas impuestas, la socialización recibida y la realidad circundante. Féminas que aparecen "en la clara encrucijada de definir su identidad y de

\footnotetext{
${ }^{3}$ Al respecto comentan Malheiro y García (2019, p. 41): “La imagen femenina [en el cine de la Transición], que a menudo desempeña una función de servicio al lucimiento de actor, enfrenta dos estereotipos principales: las "decentes" en el papel de esposas o novias, sometidas a las costumbres tradicionales de recato y moralidad; o las "libertinas", normalmente en el papel de prostitutas y casquivanas nacionales, o de turistas extranjeras". Estos autores destacan cómo la masculinidad se asocia al llamado "machismo ibérico" de tal modo que el rol del hombre se liga generalmente a la esfera sexual, con una actitud de macho permanentemente en alerta ante cualquier "oportunidad" sea dentro o fuera del matrimonio.
} 
luchar por su libertad y (... ) ofrecen a la espectadora una clara oportunidad de identificarse con personajes femeninos y modelos de mujer positivos y reales" (CASTEJÓN, 2004, p. 315).

Son muchísimos los reconocimientos que ha recibido Josefina Molina a lo largo de su trayectoria profesional, por lo que sólo destacaremos los últimos. En 2007, fue nombrada por sus compañeras de profesión Presidenta de Honor del CIMA, siglas de la Asociación de Mujeres Cineastas y de Medios Audiovisuales, una institución creada en 2006 cuyo principal objetivo es fomentar una presencia igualitaria de las cineastas y profesionales del sector audiovisual contribuyendo a una representación igualitaria y realista de la mujer dentro de los contenidos que ofrece este medio; cargo que actualmente desempeña. Queremos poner especial énfasis en los principales argumentos que señala en su página web la propia Asociación que justifica su existencia, sobre todo los tres últimos, porque coinciden plenamente con los propósitos visibles en la obra de Molina y que se pueden apreciar claramente en Función de Noche:

Por qué existe CIMA

- Porque los informes y estudios siguen poniendo de manifiesto que, a pesar de estar suficientemente cualificadas y formadas, el número de mujeres profesionales sigue estando muy por debajo del $40 \%$ y sus películas siguen siendo minoritarias.

- Porque las películas que dirigen las mujeres cuentan de media con menos de la mitad del presupuesto que las que dirigen nuestros compañeros.

- Porque si permitimos el enquistamiento de esta situación hacemos que las nuevas generaciones de mujeres no tengan referentes y no se incorporen a la profesión estableciendo el necesario relevo.

- Porque los papeles asignados a las mujeres en la ficción están supeditados a los de los hombres, tienen menos visibilidad y presencia lo que condiciona los personajes que las compañeras actrices reciben.

- Porque de esos papeles condicionados nacen referentes para la sociedad que no sólo no responden a la realidad, sino que pueden ser directamente contraproducentes para el deseable objetivo de igualdad. (CIMA, 2020) ${ }^{4}$

En julio de 2011, Josefina Molina recibió el galardón Mujer de Cine, concedido por primera vez por el Instituto de la Mujer, organismo dependiente del Ministerio de Sanidad,

\footnotetext{
${ }^{4}$ Disponible en: <https://cimamujerescineastas.es/que-es-cima/>. Acceso en: 14 de marzo de 2020.
} 
Política Social e Igualdad (Área de Igualdad) del Estado español, reconociéndose su amplia labor en el mundo del cine y su compromiso por la incorporación en igualdad de condiciones de la mujer en el terreno de la creación cultural. Ese mismo año, en octubre, la Academia de Cine Español hizo pública la concesión a esta directora del Goya de Honor 2012, los "Óscars" en España, y un mes más tarde, se le dio la Medalla al Mérito en el Trabajo. Un año después, recibió la distinción de Hija Predilecta de Andalucía, premio concedido por la Junta de Andalucía, su comunidad autónoma de nacimiento5 ${ }^{5}$ En marzo de 2015, fue elegida académica de número por la sección de Nuevas Artes de la Imagen por la Real Academia de Bellas Artes de San Fernando. Finalmente, y como colofón a su espléndida carrera le ha sido concedido el año pasado, en el 2019, el Premio Nacional de la Cinematografía.

\section{b) Contexto de producción: "Cinco horas con Mario", detonante para la película}

No hay ni un ápice de exageración al afirmar que sería imposible la realización del filme Función de noche, si Josefina Molina no hubiera sido la directora teatral de la adaptación de la novela de Miguel Delibes Cinco horas con Mario (1966) y si la actriz protagonista de la obra teatral no hubiese sido Lola Herrera. A ello, hemos de añadir la apuesta arriesgada de su productor cinematográfico, José Sámano. Contemos someramente la historia, que ha sido relatada en numerosas ocasiones tanto por la directora como por la actriz.

En 1976, se estrena Cinco horas con Mario, siendo un rotundo éxito teatral hasta tal punto que permaneció varios años seguidos en cartel y luego hubo reposiciones. El núcleo de la novela lo constituye un monólogo por parte de una mujer, Carmen Sotillos, mujer conservadora de clase media-alta, que acaba de perder a su marido, Mario, catedrático de instituto y comprometido intelectual, mientras vela su cadáver durante la noche sola en su casa, “conversación" en la que se descubren sus personalidades y los conflictos de su matrimonio, entre los que destaca la falta de comunicación entre ellos. Si bien, en general,

\footnotetext{
${ }^{5}$ En España, existen diecisiete comunidades autónomas. Una de ellas es Andalucía, a la que pertenece la provincia de Córdoba.
} 
la lectura de la obra parece llevarnos a reflexionar sobre el conflicto de las dos Españas que se enfrentaron en la guerra civil, la más conservadora (Carmen) y la progresista (Mario) y anima a ponerse del lado de la última, la magistral dirección teatral de Josefina Molina unida a la soberbia interpretación de Lola Herrera, llevan al espectador a que se resalte la figura de la mujer, en la que se ve reflejada toda una educación castradora, represora, hacia la fémina desarrollada durante la etapa franquista ${ }^{6}$.

Molina trata la historia como la de un fracaso matrimonial fruto de la incomprensión mutua, y en el que los dos son culpables a la vez que víctimas de una determinada socialización diferencial por género recibida desde la infancia. El monólogo de Carmen Sotillos, en manos de Molina, aparece como un grito desgarrado y desgarrador de alguien que necesita ser escuchada y expresar todo lo que pasa en su interior y que siempre ha callado -de hecho, sólo se ha atrevido a decirlo en voz alta ante el cadáver de su esposo, nunca cuando él estaba vivo-:

Para mí, «Cinco horas con Mario» era fundamentalmente el grito de una mujer a la que nunca se había escuchado, magistralmente recogido por Delibes. Un grito contradictorio pero necesario, similar al que colectivamente se estaba dando desde el feminismo de los años de la Transición. Por eso teñí el escenario de color violeta y por eso -con ayuda de Rafael Palmero- el decorado era de telas y formas cúbicas, como el de un ataúd por dentro, pues para mí en la obra no había sólo un cadáver, el de Mario, sino dos. El otro era el de una forma de ser mujer que tenía que desaparecer necesariamente. (MOLINA REIG, 2000, p. 89)

Tanto Josefina Molina como Lola Herrera habían recibido en sus propias carnes esa misma formación castradora, por lo que podían fácilmente identificarse con el personaje

\footnotetext{
${ }^{6}$ Coincidimos plenamente con Elvira Loma (2013, p. 246) en la siguiente reflexión: “A nuestro juicio la directora deviene en una voz femenina de protesta en la sociedad de su época y utiliza para hacerse oír la queja de Carmen Sotillo, lo que no era tan evidente en la intención de Delibes, escritor de una época anterior con otros condicionantes y otras prioridades y en la que la mujer todavía tenía pocas posibilidades de elevar su voz. Aun cuando es fiel al texto delibesiano y no altera el personaje de Carmen es evidente que la propia representación da una mayor entidad a la protagonista. La puesta en escena, con los matices que introduce la intérprete con su voz, con sus risas, con sus altibajos anímicos, con la entonación, etc. hacen a Carmen más cercana, más humana, más digna de piedad, e incluso con más motivos para quejarse. En definitiva Molina la hace un personaje más visible, más ella misma, no solo la mujer de Mario".
} 
de Carmen7. Cuando Lola Herrera llevaba unos meses interpretando a Carmen Sotillos le dio un desmayo en el escenario y reflexionó sobre qué es lo que le había pasado. Tomó conciencia de que el contar la historia de Carmen le estaba llevando a imágenes de su propia vida, a su fracaso matrimonial, a su particular falta de comunicación con su expareja, a una mala educación que le había hecho sentirse inferior, tener baja autoestima, no mirar por ella misma... En una comida en un restaurante de Madrid, le comunicó a Josefina Molina y a José Sámano lo que le pasaba. Ellos estaban trabajando en un proyecto para el cine, y Molina comentó que a ella le gustaría hablar de todo lo que estaba explicitando amargamente Lola Herrera en una película, porque afectaba a mujeres de toda una generación, la suya. Sámano estuvo dispuesto a poner el dinero y la aceptación de la expareja de Herrera, el también actor Daniel Dicenta, lograron que este filme se hiciera realidad $^{8}$.

\section{c) Análisis de Función de noche \\ c.1 Estructura organizativa, síntesis argumental}

Antes de meternos a fondo en el análisis del contenido del filme, nos interesa comentar algunos aspectos en torno a la obra cinematográfica, empezando por su propio título. Este refiere a una de las dos sesiones teatrales que diariamente se ofrecían al público. El diálogo Herrera-Dicenta, núcleo de la película, se produce justamente en el intervalo entre las dos funciones de Cinco horas con Mario, esto es, antes de que empiece la de noche, mientras Lola está en su camerino, cenando y preparándose para la actuación. Ya este hecho marca el primer eslabón de una interconexión entre teatro/cine que se va a manifestar continuamente en la película a través de su propia organización.

\footnotetext{
7 De hecho, en una entrevista que le hicieron a Josefina Molina en el 2010 preguntándole si creía que había desaparecido esa mujer educada en los valores franquistas que ella había afirmado en varias ocasiones que debía ser eliminada, responde: "Tenga usted en cuenta que yo he sido educada en los valores franquistas por las monjas escolapias. Que algunas hayamos hecho un trabajo de demolición interior en busca de la racionalidad y la libertad de pensar, no quiere decir que todas mis contemporáneas hicieran lo mismo. De vez en cuando las veo asomar resistiéndose a desaparecer, tan víctimas, tan equivocadas y tontas creyéndose tan listas como Carmen Sotillos. Me causan una sincera compasión" (CONTRERAS, 2010, p. 36).

${ }^{8}$ Función de noche. 25 Muestra Internacional de Cine y Mujeres de Pamplona. Presenta y modera María Castejón Leorza con la asistencia en la mesa de Josefina Molina y Lola Herrera (IPES Elkartea) 9 junio 2011. Disponible en: <https://www.youtube.com/watch?v=rSfv3kNVa7o>. Acceso en: 15 de marzo de 2020.
} 
Según la propia directora, Josefina Molina, la película tenía un objetivo principal:

hablar de una generación de mujeres con la pretensión de la utilidad, que pudiese servir a esa generación de mujeres a que reflexionasen sobre su propia vida y ser un testimonio sobre una época, sobre una forma de educar a las mujeres, de la vivencia de las relaciones entre mujeres y hombres en aquella época de la dictadura y (...) lo importante es que de alguna manera nos sea útil, yo creo que eso es lo que nos movió, que fuese útil y en aquel momento era necesario. (MOLINA REIG, 2011) ${ }^{9}$

La película comienza presentándonos a la actriz Lola Herrera en su camerino en un descanso entre las dos funciones diarias de Cinco horas con Mario. Este camerino será el escenario principal donde se desarrolle la película, un espacio cerrado, sin ventanas, que produce cierta sensación de claustrofobia, como agobiante será la situación que presente Lola en el filme. Al mismo tiempo, es un lugar que recoge objetos de la vida personal de la actriz: fotografías de sus hijos, de sí misma, recortes de críticas de sus representaciones... un espacio lleno de recuerdos esenciales para quien lo ocupa. Allí viene a visitarla su expareja, Daniel Dicenta, con quien había roto hacía unos quince años y con el que, a pesar de tener dos hijos en común, no se había visto desde hace un año. La conversación que mantienen Lola y Daniel es el núcleo principal del filme; ahora bien, esta es interrumpida en determinados momentos a través de saltos en el tiempo, de flashbacks.

Gracias a ellos, el público espectador conoce la visita de Lola al tribunal eclesiástico para solicitar la nulidad matrimonial -todavía no estaba aprobado el divorcio en España-; la cita con una echadora de cartas que le habla de cómo ve la relación con sus hijos y de su futuro sentimental; la consulta a un cirujano plástico sobre una operación de reducción de pecho; la salida con una amiga, Juana Ginzo, que se muestra como un modelo positivo de mujer, libre e independiente y escenas cotidianas de sus hijos donde hablan de cómo afrontan ellos las relaciones sexuales. Junto a ellos, ocupa un lugar principal la introducción de momentos de la obra teatral Cinco horas con Mario que sirven de refuerzo a los temas que va a afrontar Lola en su conversación con Daniel, ambos con cuarenta y pocos años.

\footnotetext{
9 Función de noche. 25 Muestra Internacional de Cine y Mujeres de Pamplona. Presenta y modera María Castejón Leorza con la asistencia en la mesa de Josefina Molina y Lola Herrera (IPES Elkartea) 9 junio 2011. Disponible en: <https://www.youtube.com/watch?v=rSfv3kNVa70>. Acceso en: 15 de marzo de 2020.
} 
Este tipo de estructura resultó claramente novedosa en su época, tal como comenta Natalia Contreras (2010, p. 35): “El modelo formal de su película Función de noche cuestiona los modelos narrativos tradicionales de la misma manera que, según muchas críticas de género, su obra cuestiona desde el principio las bases del cine narrativo dominante."

El filme es difícil de clasificar porque podríamos decir que es una especie de “documental de ficción”, algo que parece contradictorio en sus propios términos. Virginia Guarinos (2016, p. 95) lo describe como "una película que se mueve en el cine de ensayo, a medio camino entre la ficción y el documental, de profunda raíz docudramática". Es decir, el filme tiene la apariencia de un documental, pero los personajes centrales son actores que están interpretando.

Ahora bien, para entender este peculiar filme de ficción, que algunos lo acercan al llamado cinemá verité, conviene saber que la propia Josefina Molina afirma que tenía claro que había que darle libertad absoluta a Lola para que hablase con Daniel, su expareja, todo lo que tenía que hablar, y que la propia Lola Herrera declaró a la prensa en los momentos del estreno de la película que llegó a olvidarse de que los estaban rodando y habló de forma absolutamente espontánea sobre todas esas ideas, sentimientos y pensamientos que la había estado destrozando tanto tiempo. Exactamente, la actriz confesó: “Era importante para mí sacar toda la mierda que llevaba dentro. Aquello no fue para mí un rodaje, ya que conseguí olvidarme de que había cámaras y micros, y fui yo la que hablé ante Daniel, hombre" (ANGULO, 1981, p. 45). Mientras se hizo el rodaje, solo Josefina Molina y el técnico de sonido oían la conversación y los actores fueron grabados a partir de dos cámaras situadas detrás de los espejos de un camerino reconstruido ${ }^{10}$.

\footnotetext{
10 Función de noche. 25 Muestra Internacional de Cine y Mujeres de Pamplona. Presenta y modera María Castejón Leorza con la asistencia en la mesa de Josefina Molina y Lola Herrera (IPES Elkartea) 9 junio 2011. Disponible en: <https://www.youtube.com/watch?v=rSfv3kNVa7o >. Acceso en: 15 de marzo de 2020.
} 


\section{c.2 Contenidos temáticos}

El filme comienza con la voz en off de Lola Herrera que nos comunica la reciente visita a su camerino por parte de su expareja, Daniel Dicenta, y nos hace una primera declaración que directamente apunta a un elemento nuclear de la película: la falta de comunicación entre una pareja, ambos víctimas de la socialización-educación franquista, y las terribles consecuencias que ello trae consigo. La voz de Lola, en un tono suave, nos explica: "De repente, he sido capaz de decirle lo que tanto tiempo he tardado en confesarme a mí misma. Y me he sentido vacía, rara, después de esta larga conversación”. Averiguaremos un poco más adelante que ese "he sido capaz de decirle" nos remite a un largo periodo de tiempo constituido por los escasos años de noviazgo, los siete de matrimonio y los catorce, casi quince que llevan separados, algo que nos despierta curiosidad, desde el inicio, hacia la razón de tal mutismo, un silencio que va a estar directamente vinculado a la autonegación o autocensura desarrollada por la propia protagonista, Lola, del desvelamiento de sus sentimientos y preocupaciones más íntimas, sobre todo ante los hombres ${ }^{11}$, y por la dificultad que le ha supuesto ir deconstruyendo la configuración de su identidad personal, más cuando se ha ido encontrando con aspectos que le disgustan -sus complejos físicos, su excesivo recato, su baja autoestima en el dominio cultural-, y que, sin embargo, le cuesta apartar de su personalidad.

Ese insatisfactorio bagaje va a estar estrechamente relacionado con esos mandatos femeninos de los que hemos hablado más arriba, con esa malsana educación franquista, tan limitadora para las mujeres, siendo su interpretación de Carmen Sotillos en Cinco horas con Mario el principal motor que le ha hecho tomar conciencia del mismo. $Y$ es que, en determinados momentos de la representación, Carmen Sotillos y ella, Lola Herrera, se han fundido, se han vuelto indistinguibles los límites entre una y otra. Lola dice a Daniel que "hacer de Carmen Sotillos es hacer un poco de Lola Herrera", y le comenta que, al interpretar a Carmen, le surgen imágenes se corresponden a la vida que vivió con él. Una

\footnotetext{
${ }^{11}$ En off se escucha la voz de Lola diciendo: "Cuando estoy con un hombre nunca soy como soy. Me callo cosas. No me atrevo a decirlo todo. Siempre pienso que me compara. Y sin embargo la mayoría de las veces los hombres me dan risa. Se creen tan superiores, tan por encima, que me dan risa. Hasta creo que a veces les desprecio un poco, pero nunca se lo digo. Me imponen y al mismo tiempo sé que son más débiles que yo."
} 
vida y una posterior separación en la que se va a detectar una absoluta falta de empatía de Daniel por sus sentimientos y por las circunstancias que ha tenido que afrontar.

El primer deber inculcado a las mujeres en la época franquista era ejercer de perfectas esposas y madres, dedicar a marido y progenie toda la atención, esfuerzo y, por tanto, tiempo. No es de extrañar que cuando Lola se separa, confiese que "lo único que pensaba es que en la vida no tenía más que un futuro que era criar a mis hijos y trabajar para criarlos", y le angustiaba que ellos se pudieran sentir defraudados (ser una "buena madre"). Esa obsesión por el bienestar de sus dos hijos, Natalia y Dani, se observa en una visita a una echadora de cartas que aparece en la película, pues el principal tema de la consulta es su preocupación por la relación con ambos, y, sobre todo, en su charla con Daniel, a quien le transmite su preocupación por haber sido y ser una buena madre. Parece que sí lo ha logrado y la educación que les ha proporcionado ha conseguido que no caigan en el error de sus padres respecto a una absoluta falta de comunicación de pareja en asuntos tan importantes como la sexualidad ${ }^{12}$.

Todo lo visto en escena traduce la educación femenina que se había recibido en el franquismo hasta prácticamente su final. La generación de mujeres de la edad de Lola, con los cuarenta ya cumplidos, habían estudiado bajo la ley de Educación Primaria de 1945, que consagraba la separación de sexos en la enseñanza y en ella quedaba patente la ideología nacionalcatolicista respecto a la función social de varones y mujeres ${ }^{13}$. Idéntica mentalidad se hallaba en la Ley de Ordenación de la Enseñanza Media de 26 de febrero de 1953 que establecía "una educación separada para los alumnos de uno y otro sexo" (art. 1) y la obligatoriedad para las mujeres de materias "adecuadas a la vida del hogar y aquellas que especialmente preparen para profesiones femeninas" (art. 67). En cambio, sus hijos pertenecían a la generación que seguía su estudios bajo la Ley 14/1970, de 4 de agosto,

\footnotetext{
12 Tanto Natalia como Dani, los hijos de Lola y Daniel, aparecen en la película mientras hacen algunas actividades cotidianas (Natalia, clase de danza; Dani, en un comercio) y en off se escuchan sus voces hablando sobre cómo plantean sus relaciones afectivo-sexuales con otras personas para que el público confirme que forman parte de una generación donde hay una mayor apertura, naturalidad y libertad en abordar estas cuestiones. Son símbolo de la esperanza de los nuevos tiempos, la democracia.

13 "La educación primaria orientará, para los escolares, según sus aptitudes, para la superior formación intelectual o para la vida profesional del trabajo en la industria intelectual o para la vida profesional del trabajo en la industria y el comercio o en las actividades agrícolas. La educación primaria femenina preparará especialmente para la vida del hogar, artesanía e industrias domésticas" (art. 11).
} 
General de Educación y Financiamiento de la Reforma Educativa, que presentaba un importante compromiso por la promoción de la mujer a los niveles educativos más altos y especializados y buscaba la eliminación de cualquier tipo de discriminación para proporcionar una mayor igualdad de oportunidades educativas a toda la población (SEAGE, 1969).

El tema de la maternidad va a ocasionar la exteriorización de unos sentimientos por parte de Lola que, aunque experimentados por muchas mujeres, eran frecuentemente ocultados por estas para no ser calificadas de "mujeres desnaturalizadas", todo un insulto. La protagonista afirma que los hijos han llegado a ser una carga para ella, "una carga maravillosa, pero carga". Este desvelamiento es "moderno y feminista”, como señala Guarinos (2016, p. 96), mucho más cuando encima esta situación, como en el caso de Lola, se ha tenido que vivir sola, sin ayuda del otro progenitor, porque Daniel se desentendió por completo de la crianza de los hijos, mostrando una absoluta irresponsabilidad por su parte. Esto no sólo ha dejado a Lola exhausta, desfallecida, sin fuerzas, sino que además lo ha vivido como un impedimento para poder rehacer su vida con otra persona.

Es muy significativa la parte de la conversación entre los dos protagonistas del filme acerca de sus respectivas vivencias de la paternidad/maternidad ya que nos remite a dos tipos de socialización muy distinta por género. No queremos, por supuesto, decir que todo hombre o toda mujer tuviesen esos mismos sentimientos, pero creemos que quizá la directora estuviera interesada en reflejar los de Lola y Daniel porque los supusiese bastante extendidos entre personas de su mismo sexo. Así, Daniel admite su escaso sentimiento paternal en los primeros años de vida de sus hijos: "Quizá yo no he llegado a tener la sensación auténtica de sentirme padre hasta años transcurridos de que nuestros hijos han crecido. (... Ese “iqué bien! soy padre, vamos a celebrarlo”, yo no lo he sentido.” Añade que nunca se propuso ser padre, no se lo planteó -aunque admite que sí se alegró cuando lo fue-. Achaca el descuido absoluto de su progenie, de sus deberes paternales, a una mala racha personal y a pensar solo en él tras la ruptura.

Frente a Daniel, se eleva la figura de Lola, que se ha dejado la piel con su trabajo para llevar a su hogar el único dinero que entraba para el sustento de sus hijos. Lola, sin 
exteriorizar ira, mostrando coherencia con unos sentimientos hacia Daniel que reveló al principio del filme -"Yo hacia ti no conservo ningún mal sentimiento, o sea, yo a ti te tengo un gran cariño, me das ternura"- pregunta a su expareja si alguna vez tras su separación se planteó si sus hijos comían o no. Esa pregunta desvela las duras condiciones vitales que ha tenido que pasar durante años y que ha sufrido en silencio, su asombro y tristeza por comprobar el desapego del que fuera su pareja hacia sus hijos, desidia aún más inexplicable ante sus ojos al conocer que él, en su infancia y juventud, lo había pasado mal por la -intuida en el filme- separación o mala relación de sus padres (y con el suicidio de su madre), y estaba repitiendo en parte esa historia con su propia progenie. Ella, en cambio, se ha dedicado en cuerpo y alma a sus hijos y a su trabajo teatral. Y es entonces cuando al público se le presenta una nueva escena del monólogo de Carmen Sotillos en Cinco horas con Mario con la intención de explicar estas situaciones: “Los hombres por regla general, una vez que os echan las bendiciones, a descansar. Un seguro de fidelidad, como yo digo. Claro que con vosotros eso no rige, os largáis de parranda cuando os apetece y sanseacabó". Escena que nos va a introducir en un tema también central en la película: la infidelidad matrimonial por parte de Daniel y la resignación de Lola.

La protagonista revela, a lo largo de la conversación, que su expareja le estuvo "poniendo los cuernos" [sic], desde el principio de su matrimonio y además con diferentes mujeres, sin que además se preocupase de esconderse, más aún, con afán exhibicionista. Una actitud que nos remite al rol de amante devorador, deseoso de presentar sus conquistas femeninas como las victorias ante un torneo contra sus iguales. Este comportamiento no sólo de infidelidad sino "chulesco" en el lucimiento de sus trofeos de Daniel causó a Lola un inmenso dolor. Ella cuando se casó le había dicho a su recién estrenado marido una frase tan tremenda como "no te pido que no me engañes sino que no me entere" que nos remite a una época en la que se naturalizaba que el hombre tuviera aventuras extramatrimoniales. Por supuesto, la mujer -como dice el propio Daniel-, "con la pata quebrada y en casa", esto es, tenía que ser una persona absolutamente fiel y recatada y no podía permitirse el más mínimo desliz o era considerada una buscona y calificada con el peor calificativo posible en ese momento: “una adúltera”. Indiscutiblemente, todo ello 
nos habla de una sociedad patriarcal que medía con distinto rasero los comportamientos masculinos y los femeninos, saliendo siempre más perjudicada la mujer.

Profundicemos un poco más en el comportamiento masculino de Daniel, porque nos va a posibilitar apreciar mejor los roles clásicos impuestos a los hombres que también son muy perjudiciales para ellos. Daniel responde a Lola que "esa necesidad de enseñar a las señoras con las que estaba" se debía probablemente a sus complejos. Le recuerda que durante su matrimonio ella se movía en unos círculos de personas con la fama y éxito, y, por ende, el dinero que él hubiera deseado para él mismo, algo que le producía frustración y envidia. Se buscó un terreno en el que salir victorioso, en el que podía jactarse de estar por encima de ellos, el de las conquistas femeninas.

Observemos que esta explicación que da Daniel se corresponde perfectamente con el rol del guerrero unido al del amante. Sus relaciones con sus iguales, los otros hombres, las siente como una competición en la que, por tanto, hay vencedores y vencidos, y él necesita percibirse como el ganador en un terreno donde las mujeres son concebidas como simples objetos bajo el lema “cuántas más, mejor”. Es la leyenda de Don Juan, encandilando a una y a otra y comentando a sus amigos de forma jocosa cómo consigue que sus víctimas caigan en sus redes. Curiosamente, más tarde, Daniel comenta que Lola le parecía una mujer fantástica en la cama, que ninguna otra ni siquiera la igualó, lo que parece corroborar que esa casi obsesión por seducir a cuántas más féminas mejor no tenía nada que ver con una posible insatisfacción por las relaciones sexuales con su entonces esposa.

Ahora bien, un momento muy importante del filme es cuando Lola saca a la luz un tema tabú en la cinematografía realizada hasta entonces y en la sociedad en general: la sexualidad femenina. Y lo hace realizando una afirmación que deja a Daniel -y a su hombríatotalmente descolocado. Lola reconoce que no ha tenido un orgasmo en su vida y haberlo fingido con él infinidad de veces con la finalidad de que él se quedara contento, es decir, que no viera su ego lastimado al averiguar que no lograba satisfacer a su propia esposa. Él se ve impactado, nervioso, casi en estado de shock, al recibir esa noticia ante la cual sí enfatiza sentirse muy engañado, quizás porque se está cuestionando lo que, bajo la 
interpretación clásica de la masculinidad, constituía la principal esencial viril, su potencial sexual.

Sin embargo, la mayor tragedia es la constatación de que Lola ha sufrido una vida sexual de gran pobreza, producto también de la educación recibida donde uno de los "mandatos" que tenía la mujer era no hablar de estos temas. La falta de comunicación entre Lola y Daniel ocasionó que algo tan importante y probablemente fácil de solucionar se prolongase hasta el infinito. La protagonista cuenta su noviazgo con Daniel y coincide con el relato del amor romántico que han contado y cuentan los principales agentes socializadores a las mujeres, el "descubrir ese mundo a través del hombre con el que conociese el amor". La realidad fue bien distinta: la noche de bodas constituyó un auténtico fracaso y el matrimonio tardó en consumarse. La insatisfacción en este terreno llevó a Lola a sentirse disminuida como mujer y se culpabilizaba por no atraer sexualmente lo suficiente a Daniel al considerar que la falta de deseo o pasión hacia ella era debido a "no ser demasiado esplendorosa en la cama", algo que atribuía a sus nulas experiencias sexuales previas.

La ausencia absoluta de comunicación que ha originado este bajo autoconcepto de Lola como mujer y que le ha provocado tal dolor que aún llora cuando lo menciona, se percibe cuando Daniel cuenta cuáles habían sido sus pensamientos en el matrimonio y cuán distantes estaban de la realidad, según explica después Lola. El protagonista señala que ante determinadas actuaciones suyas en la cama, esa virginidad de la que ella le había hablado durante el noviazgo no existía ya, y que por lo tanto le había mentido. Ello se reforzaba debido a que ciertas amigas suyas le daban "informaciones" de con quiénes le había engañado con datos de fechas, y hasta de hoteles. Sin embargo, Daniel dice que no afrontó cara a cara esa posible situación porque le amaba y porque era una persona inmadura. Eso le martirizó de tal manera que ante el "buen hacer” que Lola demostraba en el plano sexual, él se sentía inhibido. Y es que en la época franquista si había un mensaje mil veces repetido hacia la mujer era el absoluto deber de llegar virgen al matrimonio, y al hombre el de asegurarse que así lo era para saber que estaba con una chica "decente". 
La moral sexual y el postulado de procreación condicionaban esencialmente el comportamiento sexual femenino. La "doble moral", típica de los sistemas tradicionales, regía los comportamientos masculinos y femeninos, creando una desigualdad flagrante. La feminidad implicaba el pertenecer a un hombre único, y conservar por lo tanto la virginidad hasta el matrimonio. (...) Aunque se aconsejaba a los hombres que se quedasen castos hasta el matrimonio, ellos podían tener relaciones íntimas anteriormente, con prostitutas, por ejemplo, sin que ello impactase su probidad. (REGUEILLET, 2004, p. 1030)

Comentábamos que estas palabras hacen a Lola romper en Ilanto. Ella declara que nunca en su vida le fue infiel, y por lo tanto se indigna ante esa falta de confianza -Lola encima se critica a sí misma el ser demasiado puritana y estrecha-, y además con la comprobación de que al final incluso en un hombre "progresista" como Daniel sigue vigente la idea de que la mujer "decente" debe mostrarse torpe, inexperta, hasta bobalicona... a riesgo de ser tachada de "libertina" o de “mujer fácil”, por eso comenta: "Qué bonito lo que acabas de decir, era lo que decían las mamás, había que mostrarse como una puritana” (... ) “entonces tenían razón esas señoras que decían que había que llegar al matrimonio sin saber nada y haciéndose la estrecha”. Él lo niega, pero sus palabras contradicen ese hecho.

Los complejos que arrastra Lola no se reducen al terreno sexual, se trasladan también al plano cultural. Lola declara a Daniel que ha envidiado que él poseía una “cultura”, mientras que ella se considera una ignorante, y que cree que él debía haberse esforzado en descubrirle nuevas cosas, en definitiva, en conseguir elevar su nivel intelectual. De hecho, señala una anécdota en la que ella dijo mal una frase y él, con poco acierto, la miró con gesto de desprecio por lo inculta que era. Esta escena del filme nos remite a la concepción franquista sobre la educación que correspondía a unos y a otras. Se privilegiaba la formación del varón, aunque esta hubiera de ajustarse, por supuesto, a su clase social; en el caso de la mujer, fuera de la clase que fuera, su destino fundamental era el de madreesposa por lo que nunca hubo gran voluntad de dotarla de sólida instrucción intelectual por parte del Estado (SIMÓN, 2010).

La conversación entre Lola y Daniel termina con una declaración conjunta de rechazo a la educación/socialización que ambos han recibido durante el Franquismo y que 
tanto ha afectado negativamente al curso de sus vidas: "a nuestra generación nos ha hecho mierda". Y ahora era duro salir adelante, por eso Lola pide desesperada un futuro, en el que ella se ve sola sin haberlo deseado -más desesperante cuando el mensaje de felicidad dado a las féminas es el de vivir en pareja, formar una familia, con una media naranja que las complete- , y lleno de paz, dejando atrás esa guerra interior que ha sentido durante tantos años. Un futuro en el que sí que sabe que no fingirá, que será ella misma, con sus virtudes y con sus defectos, y en el que aspira a parecerse, aunque sea solo un poco, a su amiga Juana.

Hemos querido dejar para el final el encuentro de Lola con su amiga Juana Ginzo con la que da un paseo desde su casa hasta el teatro del que solo aparecen imágenes mientras escuchamos la voz en off de la protagonista explicándonos cómo es Juana. El motivo es porque en el filme transmite a las mujeres un mensaje muy positivo de esperanza, de posibilidad de cambiar las cosas y de desembarazarse de una educación tan castrante como la sufrida por la mayoría de las féminas en el Franquismo. En primer lugar, Ilama la atención su aspecto físico, muy diferente al de Lola. Juana, que además es un poco mayor que ella, va vestida de manera informal, con pantalones anchos, el pelo bastante corto y sin teñir, zapatos planos... dando una imagen de comodidad.

Además, rompe con los estereotipos tradicionales de pareja, ya que tiene como pareja a un chico mucho más joven que ella. Ahora bien, la envidia sana que le tiene Lola es por haberse liberado de los mensajes represivos que sufrieron las mujeres de su generación. Juana aparece como una mujer segura de sí misma, con las ideas claras, libre, vitalista, jovial, que aconseja a Lola que "lo primero que hay que hacer es perder la reputación", ya que ese maldito término de "reputación" no ha significado más que esclavitud y opresión para las mujeres. Juana es la luz, el horizonte de esperanza, al que, sabiendo que resultará difícil de alcanzar, Lola querría llegar. Simboliza a nuestro entender la idea de que siempre se puede cambiar, de que podemos liberarnos de ropajes que nos disgustan y conseguir así una mayor felicidad o, al menos, más satisfacción con nosotras mismas. 


\section{Reflexiones finales}

La Transición supuso para la población española un punto de inflexión que le llevó a replantearse toda una forma de estar en el mundo. Nuevas leyes, normas, orientaciones emanadas de recién estrenadas instituciones no eran suficientes para transformar hábitos y costumbres que habían ido asentándose durante décadas, conformando las distintas identidades personales y colectivas. Se exigía un esfuerzo crítico y comprometido de deconstrucción de un pasado que repercutía en el presente y que condicionaba el futuro.

Muchos representantes de la cultura pusieron su granito de arena en la edificación de una nueva España más libre y humana. Y el Séptimo Arte no se quedó atrás. Como señala Jaime (2000, p. 131), “el cine español permaneció ligado a las ambiciones del país, hasta el punto de aparecer hoy como uno de los símbolos más representativos de sus preocupaciones renovadoras, de sus luchas por asentar definitivamente la democracia". Aunque pocas, debido a las presiones ideológicas de una sociedad patriarcal y conservadora como la franquista, hubo mujeres directoras que se comprometieron en cuerpo y alma, con sus obras, con su vida, en la búsqueda de nuevos horizontes de libertad especialmente para las féminas. En sus filmes, se aprecian tanto reivindicaciones sociales y políticas por parte de las mujeres, destinadas a abandonar esa ciudadanía de segunda que habían sido obligadas a abrazar, como la necesidad de sacar a la luz temas que el cine dirigido y escrito mayoritariamente por hombres había silenciado o, en el mejor de los casos, habían sido expuestos bajo una mirada ajena a la de sus protagonistas: maternidad, sexualidad femenina, violencia conyugal, control de natalidad, etc. Una de esas valientes y brillantes directoras fue Josefina Molina y una de sus películas más representativas de esta postura fue Función de noche (1981).

Función de noche (1981) se presenta como una película rupturista en múltiples aspectos: combina realidad y ficción, jugando continuamente con el papel de teatro como espejo de la vida (LOMA, 2013, p. 311); saca a la pantalla una representación femenina muy alejada de la habitual en el cine español hegemónico hasta entonces; y, sobre todo, realiza un análisis crítico de la etapa franquista a partir de cómo configuró una identidad femenina llena de represiones, ligada a mandatos patriarcales que la humillaban y menospreciaban, 
subordinada a un papel de atención a los otros (marido y progenie), y a la que se le negaba cualquier iniciativa emancipatoria. A través de la interpretación de Lola Herrera, a la valentía de desnudar ante la pantalla experiencias de su propia vida, apreciamos la necesidad de una mujer, símbolo de toda una generación, de liberarse de pensamientos y sentimientos angustiosos causados por la socialización recibida y de mostrar sus auténticos deseos:

Lola Herrera encarna el sufrimiento de generaciones de mujeres a las que «no les gusta su vida» [... ] Nos presenta el conflicto de una mujer consigo misma, su necesidad de liberarse de la carga moralizante y perversa de su educación, que le ha causado estragos impidiendo que pudiera vivir para sí misma. Por fin, [se nos muestra] la desnudez intelectual y emocional y una confrontación directa y sincera entre la identidad impuesta y los verdaderos deseos de una mujer. (CASTRO, 2009, p. 222 y 223)

La conclusión a la que llegan los dos protagonistas del filme sobre la educación que han recibido se resume en una palabra: estafa. Lola y Daniel se han sentido engañados por un sistema autoritario, represor, que socializaba a un género y a otro en unos roles estandarizados perjudiciales para el desarrollo integral de la persona. Por desgracia, bajo dichos parámetros salía perdiendo el colectivo femenino porque, como señala Loma (2013, p. 312), estamos ante "toda una generación de mujeres a las que se les enseñó a vivir a través y para el otro, olvidándose de sí mismas", tal como denuncia la propia Lola en la película, al afirmar que ha vivido para todo el mundo desde siempre, pero no para ella, pensando que su principal misión era complacer a los demás.

La película permitió a muchas mujeres verse reflejadas en las quejas y anhelos de la protagonista, probablemente cumpliendo el objetivo que se planteó la directora, facilitar un examen crítico de la educación recibida que les posibilitase, al comprobar los aspectos opresores de la libertad y el desarrollo personal, reconstruirse, superar tabúes y buscar nuevos rumbos, proponiendo un modelo positivo como el de Juana Ginzo.

Hoy en día, pasados ya cuarenta años, es cierto que se han conseguido logros en la lucha por la emancipación femenina. Sin embargo, las mujeres no podemos dormirnos en la autocomplacencia. Existe también actualmente un resurgir de una corriente conservadora y de extrema derecha, que está en fuerte crecimiento, y que desearía volver 
a tiempos pasados, siendo uno de sus enemigos declarados el feminismo. Asimismo, continuamos en sociedades patriarcales, cargados de micromachismos difíciles de detectar si no tenemos educada la llamada "mirada violeta". Trabajos como este intentan ayudar a todos y todas en esa formación de la mirada, que seguro que contribuye en que vivamos en un mundo más justo y libre.

\section{Referencias}

ALONSO, M. y FURIÓ, E. El papel de la mujer en la sociedad española. Economía, Treball i Territori, n. 19, p. 1-43, 2007.

ANGULO, J. La ficción teatral se convierte en realidad en «Función de noche». Diario El País, p. 45, 29 de septiembre de 1981.

BAUTISTA, E. Mujer y democracia en España: evolución jurídica y realidad social.

Documentación Social, nº 105, p. 49-73, 1996.

BURR, V. An introduction to social constructionism. London: Routledge, 1995.

CAPEL, R. M. Mujer y mundo laboral en el siglo XX: Perspectiva Europea. En: MARíN, T y DEL POZO, M. M. (Eds.). Las mujeres en la construcción del mundo contemporáneo. Cuenca: Diputación Provincial de Cuenca, 2002, p. 103-117.

CASTAÑEDA CEBALLOS, P. Josefina Molina. Soy feminista porque soy mujer. Meridiana. Revista del Instituto Andaluz de la Mujer, nº 11. p. 42-45, 1998.

CASTEJÓN LEORZA, M. Mujeres y cine. Las fuentes cinematográficas para el avance de la historia de las mujeres. Revista Berceo. Logroño, n 147. p. 303-327, 2004.

CASTRO GARCÍA, A. La representación de la mujer en el cine español de la Transición (1973-1982). Oviedo: KRK, 2009.

CIMA (2020). Objetivos. Disponible en: <https://cimamujerescineastas.es/que-es-cima/>. Acceso en: 14 de marzo de 2020.

CONTRERAS DE LA LLAVE, N. Entrevista con Josefina Molina, Quaderns de cine, 5, p. 33-36, 2010.

FLECHA, C. (1989). Algunos aspectos sobre la mujer en la política educativa durante el régimen de Franco. Historia de la Educación, nº 8, p. 77-89, 1989. 
FORNIELES ALCARAZ, J. Historia y novela en los primeros años de la transición. En: QUIROSA-CHEYROUZE Y MUÑOZ, R. (coord.). Historia de la transición en España. Los inicios del proceso democratizador. Madrid: Biblioteca Nueva, 2007, p. 421-431.

GALVÁN, V. La influencia de Michel Foucault en los movimientos de liberación sexual durante la Transición española. ÉNDOXA, nº 31, p. 127-144, 2013.

GUARINOS, V. Nosotras dirigimos, nosotras decidimos. Mujeres cineastas para una Transición. En: GUARINOS, V. (coord..). Apuntes de cine. Homenaje a Rafael Utrera. Madrid: Delta Publicaciones, 2016, p. 87-102.

GUICHOT-REINA, V. Socialización política, afectividad y ciudadanía: la cultura política democrática en el cine de la Transición española. Historia y Memoria de la Educación, $\mathrm{n}^{\circ}$ 5, p. 283-322, 2017.

GUICHOT-REINA, V. Mujeres en Transición. Referentes femeninos en el cine de José Luis Garci. Making Of, n 147-148, p. 48-60, 2019.

JAIME, A. Literatura y cine en España (1975-1995). Madrid: Cátedra, 2000.

LOMA MURO, E. I. (2013). Las imágenes de Josefina Molina: de la escritura literaria a la audiovisual. Córdoba: Servicio de Publicaciones de la Universidad de Córdoba, 2013.

MALHEIRO GUTIÉRREZ, X.M. y GARCÍA LEGARRA, S. Entre patriarcado y feminismo: ruptura y continuidades en el discurso social sobre género. Making Of, n 147-148, 2019.

MOLINA REIG, J. Sentada en un rincón. Valladolid: 45 Semana Internacional de Cine, 2000.

MOLINA REIG, J. Función de noche. 25 Muestra Internacional de Cine y Mujeres de Pamplona. Presenta y modera María Castejón Leorza con la asistencia en la mesa de Josefina Molina y Lola Herrera (IPES Elkartea) 9 junio 2011. Disponible en: <https://www.youtube.com/watch?v=rSfv3kNVa7o>. Acceso en: 15 de marzo de 2020.

MOORE, R. Y GILLETTE, D. La nueva masculinidad: Rey, Guerrero, Mago y Amante. Barcelona: Paidós, 1993.

MORA, E. Imagen y discurso del Año Internacional de la Mujer en la prensa regional murciana. El Futuro del Pasado, n 3, p. 185-207, 2012.

MORENO-SECO, M. Compromiso político y feminismo en el universo comunista de la Transición. Cuestiones de género: de la igualdad a la diferencia. № 8, p. 43-60, 2013.

MORENO SECO, M. Cruce de identidades: masculinidad, feminidad, religión, clase y juventud en la JOC de los años sesenta. Historia y política: Ideas, procesos y movimientos sociales, $n^{\circ} 37$, p. 147-176, 2017. 
ONU, SEMINARIO GALEGO DE EDUCACIÓN PARA LA PAZ. Educación emocional y violencia contra la mujer. Madrid: Catarata, 2006.

PÉREZ-MORENO, H. M. y GONZÁLEZ-FARACO, J. C. La sección femenina de la Falange española y su papel en la formación de la mujer rural durante la dictadura del General Franco. History of Education \& Children's Literature, IX n², p. 529-548, 2014.

RAMÍREZ GÓMEZ, D. Adaptaciones inconfesas en el cine español. Fotocinema. Revista científica de cine y fotografía, $n^{\circ} 3$. pp. 118-130, 2011. [Online], Disponible en:

http://www.revistafotocinema.com/index.php?journal=fotocinema\&page=issue\&op=view \&path[]=14. Acceso en: 15 de marzo de 2020.

REGUEILLET, A. G. Norma sexual y comportamientos cotidianos en los diez primeros años del Franquismo: noviazgo y sexualidad. Hispania, LXIV/3, n² 218, p. 1027-1042, 2004.

REIA-BAPTISTA, V. Apropiaciones mediáticas con ejemplos de cine europeo. Comunicar: Revista científica iberoamericana de comunicación y educación, nº 39, pp. 81-90, 2012.

RUZAFA ORTEGA, R. La historia a través del cine. Transición y consolidación democrática en España. Bilbao: Servicio Editorial de la Universidad del País Vasco, 2004.

SEAGE, J. El libro blanco de la educación. Boletín de la Comisión Española de la UNESCO, $\mathrm{n}^{\circ}$ 5, p. 29-35, 1969.

SIMÓN, M.E. La igualdad también se aprende. Cuestión de coeducación. Madrid: Narcea, 2011.

VALCÁRCEL, A. Feminismo para un mundo global. Madrid: Cátedra, 2008.

VILCHES, G. Las mujeres en la primera etapa de la Transición española (1975-1977). Una mirada a través de la prensa satírica. Historia del presente, $n^{\circ} 23$, p. 79-92, 2014.

WEST, C., y ZIMMERMAN, D. H. Doing Gender. Gender and Society, 1, nº 2, p. 125-151, 1987.

Recebido em: 06/03/2020

Aprovado em: 28/07/2020

Universidade do Estado de Santa Catarina - UDESC

Programa de Pós-Graduação em Educação - PPGE

Revista Linhas

Volume 21 - Número 47 - Ano 2020

revistalinhas@gmail.com 